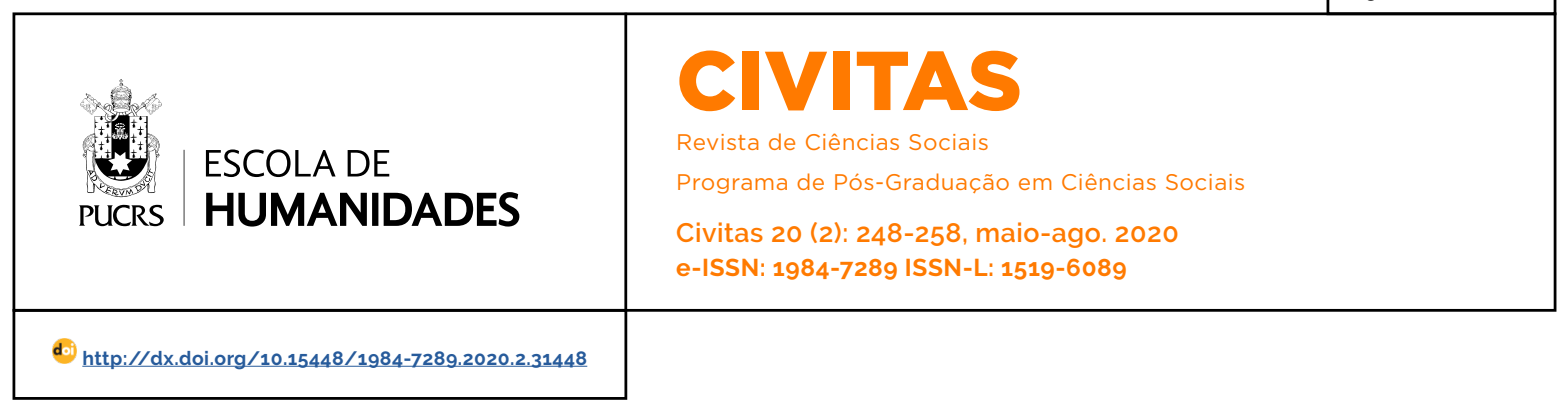

ARTIGOS/ARTICLES

\title{
Na captura de uma agência astuciosa: lições de uma etnografia com crianças sobre usos da noção de bullying
}

In capturing of a crafty agency: lessons from an ethnography with children about uses of the notion of bullying

En captura de una agencia astut: lecciones de una etnografia con niños sobre los usos de la noción de bullying

\author{
Juliane Bazzo \\ orcid.org/0000-0001-6196-3482 \\ bazzojuliane@gmail.com
}

Recebido em: 19 jul. 2018. Aprovado em: 2 out. 2019. Publicado em: 4 ago. 2020

\section{(c) (1)}

Artigo está licenciado sob forma de uma licença Creative Commons Atribuição 4.0 Internacional.
Resumo: Este artigo aborda interpelações teóricas, metodológicas e éticas levantadas ao se abraçar crianças enquanto sujeitos de pesquisa em uma etnografia da agência da noção de bullying na contemporaneidade brasileira. Para situar esses desafios em um contexto empírico, a exposição delimita como estudo de caso as conexões que as crianças hoje estabelecem entre o agenciamento desse conceito e a atribuição de apelidos pejorativos entre pares escolares.

Palavras-chave: Bullying. Agência. Infância. Educação. Etnografia.

Abstract: This paper deals with theoretical, methodological and ethical questions raised when embracing children as subjects of research in an ethnography of the agency of the bullying concept in Brazilian contemporaneity. In order to situate these challenges in an empirical context, the paper delineates as a case study the connections that children today make between the agency of this concept and the attribution of pejorative nicknames among school peers.

Keywords: Bullying. Agency. Education. Childhood. Ethnography.

Resumen: Este artículo aborda interpelaciones teóricas, metodológicas y éticas planteadas al abrazarse a niños como sujetos de investigación en una etnografía de la agencia de la noción de bullying en la contemporaneidad brasileña. Para situar estos desafíos en un contexto empirico, la exposición delimita como estudio de caso las conexiones que los niños hoy establecen entre el agenciamiento de este concepto y la atribución de apodos peyorativos entre pares escolares. Palabras clave: Bullying. Agencia. Infancia. Educación. Etnografía.

\section{Introdução}

Bullying designa em língua inglesa o ato decorrente do substantivo bully, que significa algo próximo a "brigão" ou "valentão" em português. De autoria atribuída ao sueco Dan Olweus (2006), professor e pesquisador em psicologia na Universidade de Bergen (Noruega), o bullying é um construto científico da década de 1970, que se alastrou mundialmente desde então, na função de nomear intimidações repetitivas entre pares escolares. No Brasil, o conceito de Olweus (2006) experimenta uma vultosa popularização somente ao longo dos anos 2000.

Minha pesquisa de doutoramento em Antropologia Social buscou destrinchar, sob uma perspectiva etnográfica, as "agências" (Ortner 2007) 
que a noção de bullying tem recebido no cotidiano brasileiro, especialmente desde o estado do Rio Grande do Sul (Bazzo 2018). Nesse quadro, o estudo atentou para a atuação dos "empreendedores morais" (Becker 2008): indivíduos, instituições, iniciativas e documentos responsáveis hoje por agenciar esse conceito em uma variedade de contextos e, assim, alavancar uma série de filosofias, políticas e práticas, de fins diversificados.

Em tal panorama, as investidas de campo efetuadas entre 2014 e 2017 - incluiram pesquisa em órgãos públicos e redes científicas, principalmente na capital Porto Alegre (RS), como também a análise de conteúdos midiáticos, de produtos de mercado e de documentos de referência, tanto nacionais quanto internacionais, em que o bullying aparece como mote. Não obstante, uma parte crucial dessa imersão ocorreu em duas escolas, uma pública e outra privada, situadas na região de Gramado e Canela, municípios de pequeno porte da Serra Gaúcha, onde residi por três anos.

Este artigo coloca em relevo justamente a empreitada de campo nos ambientes escolares, uma vez que aborda interpelações teóricas, metodológicas e éticas levantadas ao se abraçar crianças enquanto sujeitos de pesquisa nesses universos. Para situar empiricamente tais desafios, a exposição delimita como estudo de caso a hoje corriqueira agência da noção de bullying por crianças para rechaçar a costumeira atribuição de apelidos pejorativos entre pares nos espaços educacionais. Tal recorte deriva de minha atenção etnográfica às "práticas culturais" infanto-juvenis cristalizadas atualmente nas chamadas "zoeiras" nas escolas (Pereira 2010). Com esse termo, crianças e jovens estudantes de diferentes regiões brasileiras têm definido suas relações de "socialidade jocosa", as quais contemplam, mas não se restringem, a "gozações" de feitio discriminatório classificadas como bullying.

A exemplo da etnografia de Noel (2009) sobre conflitualidades cotidianas no cenário escolar argentino, meu estudo não se propôs a uma "comparação sistemática" entre as instituições de ensino pesquisadas. A análise serviu-se, sim, da "iluminação reciproca" propiciada pela inserção simultânea de finalidade comum nesses ambientes. Nesse sentido, identifiquei entre as duas escolas mais traços de similaridade que de diferença nos agenciamentos da noção de bullying, sintonizados, por sua vez, com os dados coletados nos demais campos investigados.

\section{Observações na escola pública}

Um dos espaços escolares no qual me introduzi como pesquisadora é uma instituição pública estadual, à época do estudo com cerca de 70 educadores e um mil alunos de camadas socioeconômicas médias, distribuidos entre o Ensino Fundamental, o Ensino Médio e a Educação de Jovens e Adultos. As observações nessa entidade se articularam pela imersão no cotidiano de três turmas discentes.

Considerada a definição do Estatuto da Criança e do Adolescente (Lei n. 8.069/1990) de que são crianças os individuos de até 12 anos de idade incompletos, um dos grupos sob observação reunia infantes stricto sensu e outro abrangia sujeitos que tinham acabado de deixar essa condição. Dessa forma, entendeu-se oportuno abarcar ambos na análise aqui desenvolvida. ${ }^{2}$ Nesse contexto, inseri-me em uma turma de segundo ano e em outra de sétimo ano do Ensino Fundamental, as quais contavam com alunos de, em média, 7 e 12 anos, respectivamente. Ao longo de um ano letivo completo, permaneci em média dois meses e meio em cada uma delas, com um mínimo de duas visitas semanais.

A inserção nas turmas ocorreu sob chancela da equipe diretiva e dos respectivos docentes que, nas primeiras visitas, explicaram aos estudantes o propósito de minha presença, com adaptações para as faixas de idade envolvidas. No transcorrer dos encontros, fui procurando ocupar lugares diferentes no interior das salas de aula, com o fim de variar ângulos de observação. Dia após dia, meu trabalho quase sempre iniciou pelo desenho de um espelho de classe, para exercitar o reconhecimento dos estudantes pelo nome, identificar os locais geralmente ocupados por eles, bem como mapear as socialidades tecidas nesse entorno.

2 O terceiro grupo observado englobava jovens, já estudantes de Ensino Médio. 
Com a expansão da convivência, além de reflexões escritas em diários de campo, desenvolvi sociogramas para pensar acerca dos relacionamentos entre os alunos. Nessas figuras, busquei delimitar os grupos internos de cada turma e os vínculos de dominância, subalternidade, oposição e solidariedade entre eles. Assim, entre escrita e desenho, registrei em que tipos de circunstâncias o construto do bullying surgia; em que medida minha presença como pesquisadora do tema o suscitava; assim como situações nas quais, embora favoráveis ao agenciamento, o conceito simplesmente não dava o ar da graça. A Figura 1 exemplifica um desses sociogramas.

Figura 1 - Sociograma de um grupo discente 3

Turma do segundo ano

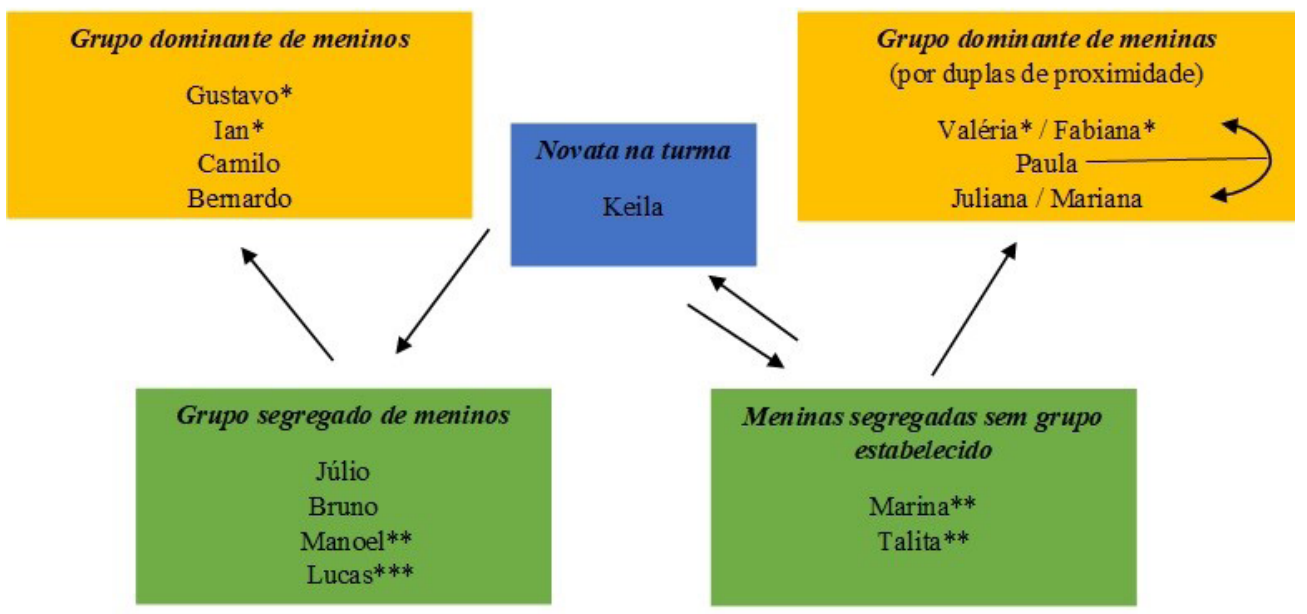

$$
\begin{gathered}
\text { Legenda: } \\
\text { * Potencial ofensor } \\
\text { ** Potencial ofendido } \\
* * * * \text { Potencial ofendido e pária na turma como um todo } \\
\rightarrow \text { Tentativa de entrosamento }
\end{gathered}
$$

Fonte: Elaborado pela autora.

Certas peculiaridades a cercar meu trabalho de observação mostraram-se similares àquelas de outras etnografias realizadas com crianças e adolescentes, em escolas ou não (Lewis 2015; Cohn 2013; Horn 2013). À semelhança dessas investigações, embora apresentada às turmas como pesquisadora, passei muito brevemente a ser enquadrada como docente pelos estudantes. Diante disso, especialmente na aproximação com o alunado, esforcei-me em demonstrar que minha posição não era de autoridade ou de avaliação, elementos esses conectados à docência. Tal investimento, em meu caso, assumia uma feição singular, dado meu tema de estudo remeter-se a comportamentos hoje condenáveis no ambiente escolar.

No começo das observações, a despeito do zelo em esclarecer meu papel não fiscalizador, os estudantes evidenciaram desconfiança das notas que fazia em minha caderneta. Os menores me perguntavam se registrava os nomes dos que conversavam ou bagunçavam durante as atividades letivas. Esse clima se desanuviou, entretanto, à medida que lhes dei provas de que não estava ali para monitorá-los. Entre os maiores, um momento propício para tanto se configurava quando, na ausência transitória de um professor, pequenas regras eram infringidas e, perante isso, eu mantinha discrição.

Em linha com as etnografias mencionadas

3 Os nomes expostos no desenho são todos fictícios. 
acima, minhas observações entre os infantes, participantes ou não, procuraram considerar outros recursos expressivos para além da fala. Dessa maneira, brincadeiras e jogos; desenhos, danças e encenações; risos e choros; posturas de isolamento e interatividade, todos marcantes na rotina infantil, receberam tanta atenção quanto palavras ditas. Certamente, tais elementos se evidenciam entre jovens, mas em meio às crianças alcançam uma pungência peculiar, propícia ao investigador, segundo Horn $(2013,5)$, na tarefa de traçar "[...] estratégias para [...] compreender as culturas infantis e o seu modo de ser e de estar no mundo".

Para essa autora, cônscio desses códigos, o etnógrafo pode, antes de tudo, aproximar-se das crianças de um modo por elas aprovado. Esse consentimento, não pautado pela assinatura de documentos, ocorre pela "convivência ética" (Horn 2013, 5), que leva em conta linguagens singulares e, assim, respeita termos relacionais diferenciados daqueles existentes entre adultos. Tal conjuntura esclarece por que a entrevista estruturada individual pode ser improdutiva na pesquisa antropológica com crianças. A atmosfera demandada por essa técnica, com hora e lugar marcado, bem como exigência de sentar-se por certo tempo, acaba por obstruir as formas expressivas infantis, cuja preciosidade é melhor captada por observações e conversas informais.

\section{Grupos focais na escola privada}

Ao espaço público de ensino, aliou-se minha inserção em um colégio particular, integrante de um conglomerado educativo de atuação nacional. A unidade em que o estudo aconteceu, ao longo de um semestre, reunia naquele momento em torno de 50 educadores e 400 alunos, alocados entre Educação Infantil, Ensino Fundamental, Ensino Médio e Profissionalizante. Os estudantes também provinham de classes médias, porém, ocupavam com mais recorrência estratos superiores desse segmento em relação aos discentes da escola estatal investigada.

A pesquisa no universo particular de ensino viabilizou-se por meio da organização não go- vernamental porto-alegrense Mahatma - Paz nas Escolas que, à época, promovia gratuitamente a prática da meditação em cerca de 300 instituições de ensino pelo Brasil. ${ }^{4}$ Minha iniciativa em procurar essa entidade, cuja atuação incluía a Serra Gaúcha, pautou-se pela possibilidade de identificar, graças à amplitude e singularidade de seu trabalho, um ambiente educativo capaz de gerar contrastes analíticos factiveis com a escola pública pesquisada.

Nesse sentido, o colégio que me foi indicado pela organização, além de privado, inseria a meditação em um conjunto de ações escolares a reverberar filosofias contemporâneas tais como a "cultura de paz" e o "aprendizado socioemocional". Dentre outros objetivos, iniciativas inspiradas nessa direção vêm almejando coibir comportamentos entendidos como bullying, sob adesões e restrições (para um debate crítico, ver Smolka et al. 2015). De qualquer modo, trata-se de uma proposta que não existia, sistematizada, na instituição estatal sob estudo.

Dessa maneira, estabeleceu-se na escola particular um grupo de controle produtivo, mas que exigiu uma estratégia de pesquisa diferenciada da empregada no colégio público. Isso deveu-se tanto às minhas possibilidades temporais de dividir-me para a investigação simultânea de duas realidades educativas, quanto ao espaço de inserção ofertado pela instituição privada. Ajustada a tal conjuntura, ao longo de um semestre, realizei quatro grupos focais com alunos de duas turmas de $5 .^{\circ}$ ano do Ensino Fundamental, ambas dentre as engajadas na prática da meditação há mais tempo na escola.

Em etnografias do campo da educação, o grupo focal tem aparição recorrente como técnica de pesquisa - alguns usos recentes estão em Lewis (2015), bem como em Maggie e Prado (2014). No caso específico de sua realização com crianças, o grupo focal se revela vantajoso porque os participantes, para além de conversarem com o investigador, dialogam, sobretudo, entre si e em seus próprios termos, quando confortáveis. Em busca de tal fluidez, segui o conselho de Lewis (2015) sobre deixar claro aos estudantes a não

4 Essa instituição interrompeu suas atividades no final do ano de 2017, quando eu também finalizava meu doutoramento. Para saber mais, recomendo buscar na rede social Facebook por Mahatma Meditação. 
implicação avaliativa da atividade, bem como a premissa de anonimato de tudo que ali seria dito. Uma vez criado esse ambiente, essa autora afirma que a "[...] técnica [...] abre uma ampla possibilidade de negociações de sentido em que o individuo e sua carga cultural são constantemente interpelados pelo grupo" (Lewis 2015, 259).

Cada grupo focal durou em média uma hora, com o envolvimento de quatro participantes de uma mesma turma, na faixa dos 10 anos de idade, individualmente engajados ou não na prática meditativa, visto a adesão ser voluntária. As questões postas a eles foram adaptadas a partir das exploradas em entrevistas estruturadas individuais, de respostas abertas, efetuadas com jovens e adultos na escola pública e na privada. $O$ quadro 1 reúne exemplos dessas interpelações.

Quadro 1 - Questões-chave de pesquisa

\begin{tabular}{l|l}
1 & O que é bullying para você? \\
\hline 2 & Você se recorda de seu primeiro contato com a noção de bullying? \\
\hline 3 & $\begin{array}{l}\text { Que fatores você vê como favoráveis ao reconhecimento de determinados comportamentos, sem um nome no } \\
\text { passado, como bullying? }\end{array}$ \\
\hline 4 & Você considera ter sido autor ou alvo de condutas hoje classificadas como bullying em alguma situação? \\
\hline 5 & Qual o episódio mais marcante enquadrado como bullying de que você se lembra? \\
\hline 6 & $\begin{array}{l}\text { Você verifica relações entre a difusão da ideia de bullying e a massificação das tecnologias de informação e } \\
\text { comunicação? }\end{array}$ \\
\hline 7 & Você considera que a noção de bullying abrange preconceitos e discriminações presentes na sociedade? \\
\hline 8 & $\begin{array}{l}\text { Que iniciativas você considera eficientes para a prevenção e o combate daquilo que ven sendo chamado de } \\
\text { bullying? }\end{array}$
\end{tabular}

Fonte: Elaborado pela autora.

Como as intervenções na entidade privada tiveram caráter mais circunscrito, optei pelas facilidades da gravação sonora para os grupos focais, nos quais o registro escrito fica dificultado pela interlocução simultânea dos participantes. Na instituição estatal, ao contrário, o gravador mostrava-se um impeditivo à fluência do trabalho de campo de maior prazo, não só por inibir a espontaneidade dos indivíduos no cotidiano, mas também porque a mim me parecia mais ágil e efetivo fazer registros escritos imediatos em diários de campo daquilo que, dia sim, dia não, vivenciava na escola.

\section{Da atenção ética}

No transcorrer de meu doutoramento, esteve em ação um grupo de trabalho, capitaneado a partir de 2013 pelo Fórum das Associações de Ciências Humanas e Sociais (FCHSSA), voltado à confecção de uma resolução sobre ética específica aos estudos dessas áreas do conhecimento. Esse esforço decorreu da discordância quanto à hegemonia de critérios biomédicos, aplicados a quaisquer investigações com seres humanos, por parte da Comissão Nacional de Ética em Pesquisa (Conep), subordinada ao Ministério da Saúde (Sarti et al. 2017).
Em fins de 2014, esse grupo de trabalho apresentou uma minuta de resolução considerada adequada aos seus fins que, a principio, foi inteiramente rejeitada pela Conep. Em virtude disso, o documento acabou levado em 2015 à consulta pública e, graças a um volume expressivo de manifestações, terminou aprovado em sua quase totalidade no ano seguinte, como Resolução n. 510/2016 do Conselho Nacional de Saúde (CNS). Porém, antes que fosse possivel conferir operacionalidade a tal instrumento, a Conep desfez o grupo de trabalho encabeçado pelo FCHSSA. Até a finalização de meu estudo, tal controvérsia continuava em aberto, com as associações integrantes do fórum ainda militantes no sentido de reocupar seu espaço retirado (Sarti et al. 2017).

Solidária a essa disputa, optei por não submeter minha proposta de pesquisa à apreciação de comitê universitário de ética. Obviamente, essa escolha teve um facilitador: nenhuma das instituições nas quais ingressei para a efetuação do trabalho de campo exigiu-me tal submissão. A decisão por esse caminho, entretanto, não implicou, em hipótese alguma, qualquer desatenção à ética; muito ao contrário, o estudo cercou-se de um conjunto de cuidados. 
O primeiro deles diz respeito à investigação nas instituições de ensino com crianças e adolescentes em situação de menoridade legal. Em ambas as escolas nas quais ingressei, prestaram-se esclarecimentos sobre minha atividade enquanto pesquisadora a pais e responsáveis, seguidos pela assinatura de termos de consentimento livre e esclarecido. Tal procedimento coadunou-se, em primeira instância, com medidas de proteção e de tutela estabelecidas, respectivamente, pelo Estatuto da Criança e do Adolescente (Lei n. 8.069/1990) e pelo Código Civil Brasileiro (Lei n. 10.406/2002).

Seja no universo privado de ensino, seja no público, há no estudo o resguardo do anonimato, tanto das escolas, quanto dos interlocutores que nelas dialogaram comigo, em situação de menoridade legal ou não. Entendeu-se que tal postura seria a mais apropriada para preservar a identidade, a privacidade e a confiança que todos eles depositaram em mim, ao me confidenciarem episódios de vida muitas vezes dolorosos e constrangedores, não apenas a si próprios, mas a terceiros. Trata-se de um cuidado imprescindivel em espaços institucionais em que não raro o relato de um sujeito implica outros, ainda mais em cidades pequenas, onde há intensivo grau de conhecimento entre pessoas.

Em virtude disso, ao problematizar situações que ouvi ou presenciei, além de empregar nomes fictícios, precisei lançar mão do recurso de modificação de certas circunstâncias sem, contudo, impactar o campo semântico coberto pelos fatos, algo fundamental à consistência reflexiva. Dou um exemplo por excelência: as dinâmicas de agenciamento do bullying comumente envolvem, como já dito, a atribuição de apelidos pejorativos que, se revelados, fatalmente permitiriam a identificação de certos indivíduos por outros. Ao mesmo tempo, seria danoso analiticamente ocultar tais alcunhas, posto parte intrínseca dos processos em estudo. O que importa, no entanto, não reside nos cognomes em si, mas nos significados que carregam. Assim, a despeito de sua substituição por outros apelidos, priorizou-se a manutenção de significado, que é o realmente interessante ao exame antropológico.

\section{Na captura de uma agência astuciosa}

Para situar em um contexto empírico as demandas teóricas, metodológicas e éticas de minha investigação antropológica com crianças, quero compartilhar agora a história de Marina. Em meio aos seus colegas de turma em fase de alfabetização, Marina se diferenciava: pela vaidade, desenvoltura e liderança. la à escola sempre adornada, com maquiagem e outros adereços. Mesmo ainda sem saber contar direito, comercializava docinhos que ela mesma fabricava. Era estudante destacada, fato que fazia a professora lhe convocar constantemente para auxiliar outras crianças. Quando a docente não estava por perto, a maioria dos colegas reconhecia em Marina alguém capaz de ajudá-los em necessidades individuais ou de restabelecer a ordem em conflitos coletivos.

Fartamente comunicativa, Marina não demorou a se entrosar comigo. Conversava sobre assuntos dos mais diversos, dentre eles, minha própria pesquisa, sobre a qual demonstrava curiosidade. Certo dia, perguntou-me: "Profe, como a gente tá de bullying?". 5 Fui pega de surpresa, ao que ela reiterou: "Disso que tu tá estudando, de bullying, na turma". Devolvi, então, o questionamento: "Você acha que tem bullying aqui?". De imediato, relatou-me que, no ano anterior, possuía um colega, já egresso, que lhe dizia cotidianamente: "Marina, sua baleia!". E completou sobre o tempo presente: "Na nossa turma, acho que não tem bullying. Só um colega me chamou de gorda uma vez".

No período em que acompanhei Marina na escola, estava em crise o relacionamento dela com sua melhor amiga, Valéria. Naquele ano, essa colega havia se aproximado de uma outra Fabiana - e ambas vinham rejeitando a presença de Marina. Em um certo recreio, observei a tentativa de Marina em participar de uma brincadeira capitaneada pelas duas meninas, junto de outras garotas. A antes melhor amiga de Marina vetou

5 "Profe", diminutivo de professora, configura um vocativo empregado por alunos e docentes no cotidiano escolar brasileiro. 
sua integração, dizendo-lhe: "Minha mãe disse pra eu não brincar com você porque tu és muito chata". Marina virou as costas e, com o semblante profundamente entristecido, sentou-se ao meu lado, em um dos bancos do pátio.

Confidenciou-me não ser a primeira vez que tais advertências the eram dirigidas: "Ela era minha melhor amiga e agora é inimiga. Eu não sei por quê. Outro dia, ela ainda falou 'tu é gorda, tu é negra e minha mãe disse que não é pra eu brincar com você'". Marina, de fato, detinha forma corporal ligeiramente desviante de padrões hoje impostos de magreza. Mas, a observação sobre a cor da pele me gerou estranhamento por não refletir, à primeira vista, o fenótipo da menina. Perguntei-lhe então: "E tu, considera que é negra?". Ela respondeu que não, mas me contou, no decorrer de nossa conversa, que um de seus avôs era e que, talvez, se originassem daí as colocações de Valéria. "Sabe o que eu acho? Que elas têm inveja de mim, do meu jeito, porque sou mais adulta", conjecturou ao final.

A despeito das animosidades, houve situações em que verifiquei Fabiana e Valéria buscarem a companhia de Marina. Isso acontecia, quase sempre, quando as duas primeiras sentiam necessidade de auxilio em alguma tarefa de sala de aula. Todavia, testemunhei uma vez em que Marina conseguiu barganhar a atenção delas durante um recreio: foi no dia em que trouxe à escola um laptop de brinquedo que havia ganho de presente. Não só Valéria e Fabiana se interessaram, mas outras diversas crianças rodearam Marina no pátio. No entanto, havia nesse contexto um concorrente de peso: um parquinho novo na escola. Os estudantes, então reunidos em torno do laptop, logo se dirigiram para lá.

Tudo corria bem: praticamente todos os alunos da turma estavam brincando juntos, algo incomum. A certa altura, contudo, algumas crianças começaram a pedir a ajuda de Marina, posto não se sentirem seguras para certas manobras que as demais estavam fazendo no parquinho. A garota, como sempre, demonstrou-se prestativa. Entretanto, sua postura não agradava a todos. Alguns dias antes, Fabiana já a tinha admoestado: "Se você quer que eles [colegas] aprendam tem que deixar irem sozinhos". Mas, naquele dia, foi um dos garotos, Bruno, quem se embrabeceu diante do protagonismo de Marina. Colérico, o menino exclamou:

\footnotetext{
- Sua gorducha!

- Tu sabias que isso é bullying, Bruno? - falou firmemente Marina, com as mãos na cintura, após lançar um rápido olhar para mim.
}

- Parece a Dona Redonda, vai estourar! - prosseguiu sem intimidação o garoto, que conquistou expressivas risadas dos colegas em volta.

Para ultrajar Marina, Bruno metaforizou uma personagem de "Saramandaia", novela de Dias Gomes exibida pela Rede Globo em 1976, objeto de refilmagem da emissora em 2013. Na trama, Dona Redonda era uma mulher que comia sem parar e, devido a isso, acaba por explodir, perfazendo uma das cenas emblemáticas dessa produção televisiva. Ao receber essa afronta, Marina não prosseguiu no embate com Bruno. Apanhou seu laptop e se retirou para um canto, acompanhada de algumas garotas interessadas em explorar seu mais novo brinquedo.

\section{Apelidos: vetores de agência}

Em meus diários de campo, os apelidos pipocam a todo tempo em meio às vivências estudantis registradas. Não me causou estranheza, portanto, a repetição de um ponto de debate nas discussões contemporâneas que presenciei entre profissionais da educação: como controlara superabundância desses termos nos ambientes de ensino para frear o bullying?

Muito antes da popularização desse construto, não obstante, tais alcunhas mostram ser parte integrante da socialidade infanto-juvenil. Em artigo de 1944, Fernandes (2004) já apontava a centralidade delas no cotidiano das "trocinhas", agrupamentos de crianças e adolescentes que, à época, povoavam ruas de bairros populares paulistanos. Tem-se ai uma versão primeva do que, atualmente, crianças e adolescentes chamam de "zoeiras" (Pereira 2010), uma marca de suas relações escolares.

Os educadores sabem, melhor que ninguém, que os apelidos têm um espaço longamente de- 
marcado no cotidiano dos ambientes de ensino. Assim, nos debates que testemunhei, os professores nunca chegavam a respostas fechadas à pergunta colocada na abertura desta seção. As suas próprias falas, em maioria, reconheciam a fluidez desses cognomes que, à primeira vista, podiam soar tanto humilhantes, quanto inofensivos, sempre sob a possibilidade de, mais tarde, revelarem-se em contrário.

Identificava-se, portanto, nos debates docentes um atributo fundamental aos apelidos: a contingência que, na atualidade, também repercute sobre a agência da noção de bullying. Na narrativa das vivências de Marina, verifica-se que sobre ela recaem termos vexatórios considerados clássicos pelas comunidades escolares na intimidação entre pares: baleia e gorducha, em referência à obesidade enquanto marcador de "desvio" (Velho 1981) de um certo status quo. O domínio público, todavia, não garante qualquer estabilidade a essas expressões que, embora se perenizem, também se transmutam em sinonímias das mais elaboradas.

Ao prosseguir na história de Marina, vê-se que, perante o insulto de gorducha, ela responde à "acusação" (Velho 1981) do colega com outra, ciente de minha presença enquanto investigadora daquele tipo de acontecimento. "Tu sabias que isso é bullying?", indagou de modo responsivo a garota. Uma vez desafiado, Bruno trabalha com o imprevisto e apela para o não óbvio: evoca como ofensa a personagem televisiva Dona Redonda. Dessa forma, consegue roubar risadas generosas das testemunhas ao redor do confronto e, em seguida, calar Marina.

Em minha investigação, problematizei episódios classificados como bullying na contemporaneidade brasileira como "rituais acusatórios" (Velho 1981). Nesses eventos, com recorrência, o conceito em foco materializa-se como uma contra-acusação, posto quase sempre agenciado em resposta a uma primeira imputação. Isso se deve à capacidade impar que o construto vem demonstrando de imantar-se a marcadores de "desvio" dos mais diversos - como os estéticos e os étnico-raciais referidos na história de Marina -, eles mesmos mobilizadores de longa data de uma profusão de "acusações", a sustentar uma conjuntura de segregação no Brasil.

Uma vez na posição de ritos, em concordância com abordagem de Tambiah (1985), as ocorrên- cias enquadradas como bullying demonstram-se recheadas de um componente contingencial a eles fundamental: as figuras de linguagem e, dentre estas, especialmente as metáforas, capazes de condensar várias e inusitadas camadas de interpretação - vide a inculpação de Dona Redonda. Tais recursos abastecem o idioma ritual em sua economia e agilidade, em prol de funções cruciais como problematizar dilemas, expressar conflitos e trabalhar relações de poder.

Se os rituais portam um vocabulário particular, do mesmo modo se definem por comportamentos singulares, os dois não raros reversos a protocolos publicamente naturalizados (Tambiah 1985). Assim sendo, há que se considerar a conduta indicadora de eficácia discursiva para práticas hoje tipificadas como bullying escolar: a risada corporificada. A exemplo das metáforas a circundar os apelidos, o riso não se presta à previsibilidade. Sob viés batesoniano, Lagrou (2009, 172) explica que o propósito de fazer rir pressupõe ser "[...] inferido pelos envolvidos ao longo do desenrolar da cena".

Nem tudo, porém, é flutuante nesse quadro. Os rituais de "agressividade verbal" em análise aqui, como quaisquer outros, perfazem uma "reencenação da vida": apontam "sistemas de valores" a orientar a ação dos sujeitos envolvidos e, especialmente, tensões em curso nesses arranjos (Duarte 1981). Por conseguinte, chega-se ao paradoxo intrínseco aos ritos: se esses só podem ser compreendidos contextualmente, há neles sempre um nivel de redundância, que trabalha pelo didatismo e pela eficiência. Esse conteúdo de repetição decorre, justamente, da cosmologia na qual os agentes se encontram imiscuídos que, uma vez iluminada etnograficamente, pode revelar dinâmicas de humilhação, mas também de mutualidade ou até mesmo de insurgência mobilizadas por apelidos, apesar da impossibilidade de controlar a fluidez deles no mundo social.

\section{À guisa de classificação}

O quadro 2 apresenta um apanhado de apelidos pejorativos registrados ao longo de meu trabalho de campo em instituições de ensino. 
Quadro 2 - Categorização de apelidos pejorativos no universo escolar de pesquisa*

\begin{tabular}{|c|c|c|c|}
\hline $\begin{array}{l}\text { Referências } \\
\text { étnico-raciais }\end{array}$ & $\begin{array}{l}\text { Referências de gênero e } \\
\text { orientação sexual }\end{array}$ & $\begin{array}{l}\text { Referências } \\
\text { socioeconômicas }\end{array}$ & $\begin{array}{l}\text { Referências } \\
\text { estéticas }\end{array}$ \\
\hline $\begin{array}{c}\text { Cabelo duro; Indiazinha; } \\
\text { Moreninho; Negro; Pelé; } \\
\text { Picolé de piche; Preta } \\
\text { imunda. }\end{array}$ & $\begin{array}{l}\text { Bicha; Bichinha; Boiola; } \\
\text { Gay; Guri; Lésbica; } \\
\text { Menininha; Menino; } \\
\text { Mulherzinha; Puta; Puto; } \\
\text { Vagabunda; Traveco; } \\
\text { Travecão. }\end{array}$ & $\begin{array}{l}\text { Filhinho de papai; Rico; } \\
\text { Riquinho; Vileiro } \\
\text { (individuo residente em } \\
\text { áreas urbanas } \\
\text { empobrecidas). }\end{array}$ & $\begin{array}{l}\text { Baixinho; Boca arregaçada; } \\
\text { Branquela; Bulímica; } \\
\text { Bunduda; Espeto; Feia; } \\
\text { Ferrugem; Foguinho; } \\
\text { Gorducha; Grandão; } \\
\text { Inchada; Jeca; Nanico; } \\
\text { Obeso mórbido; Orelhudo; } \\
\text { Palito de dente; Quatro } \\
\text { olhos; Ridicula; Seca; } \\
\text { Toquinho; Vareta. }\end{array}$ \\
\hline $\begin{array}{c}\text { Referências } \\
\text { comportamentais }\end{array}$ & $\begin{array}{c}\text { Referências de higiene } \\
\text { pessoal }\end{array}$ & $\begin{array}{c}\text { Referências } \\
\text { animais }\end{array}$ & Referências figurativas \\
\hline $\begin{array}{c}\text { Bizarro; Cagoeta; Dedo- } \\
\text { duro; Esquisito; Guria do } \\
\text { demônio; Idiota; Louco; } \\
\text { Nerd (individuo } \\
\text { considerado estudioso em } \\
\text { demasia); Retardado. }\end{array}$ & Fedorento; Imundo; Sujo. & $\begin{array}{c}\text { Baleia (assassina, chupeta } \\
\text { de, isca de); Boca de bicho; } \\
\text { Burro; Castor; Coruja; } \\
\text { Dumbo (personagem de } \\
\text { desenho animado); Galinha; } \\
\text { Girafa; Leão (juba de); } \\
\text { Macaco; Mico-Leão- } \\
\text { Dourado; Pata (choca); } \\
\text { Piolho; Porca (gorda); Rato; } \\
\text { Veado. }\end{array}$ & $\begin{array}{l}\text { ET; Doente; Lixo; LV } \\
\text { (Louis Vuitton); Merda; } \\
\text { Múmia; Smurf (personagem } \\
\text { de desenho animado); } \\
\text { Victor Hugo; Zumbi; além } \\
\text { da replicação de termos } \\
\text { pejorativos diversos que } \\
\text { recaem sobre familiares. }\end{array}$ \\
\hline
\end{tabular}

* Em geral, foram mantidas as marcações de gênero conforme os apelidos a mim se apresentaram.

Fonte: Elaborado pela autora.

Graças a um exercício classificatório, verificou-se que uma expressiva quantidade desses apelidos se cola, de imediato, a "categorias de acusação" de "desvio" (Velho 1981) históricas na sociedade brasileira e, ao mesmo tempo, em grande tensão nos anos recentes devido a transformações sociopolíticas no país. Essas mudanças, em boa parte, alavancaram-se por intervenções estatais pioneiras em favor da inclusão econômica e da diversidade sociocultural durante os mandatos presidenciais do Partido dos Trabalhadores (2003-2016). Tais politicas encontraram nas instituições de ensino espaços essenciais de operacionalização. ${ }^{6}$

Boa parte dos termos vexatórios identificados refere-se, dessa forma, a desigualdades étnico-raciais, de gênero, de orientação sexual, socioeconômicas e estéticas. No grupo de apelidos focados em atributos comportamentais, por sua vez, vê-se como pano de fundo outros três tradicionais tipos de imputações: em torno da capacidade cognitiva, da deficiência e da religiosidade dos sujeitos. Tal resultado reflete uma sociedade de herança escravista, que se pensa elitizada, branca, masculina, heteronormativa, corporalmente escultural e intelectualmente racional, tendo neste conjunto de características um padrão idealizado de "normalidade" desejável (Souza 2009).

Ainda no levantamento que realizei, emergiram três coletivos singulares de apelidos, cujo ponto comum reside no caráter de transversalidade em relação aos demais já citados. Um primeiro grupo nesse status longitudinal engloba termos injuriosos referentes à higiene pessoal. De acordo com Elias e Scotson (2000), polemizar a sujeira coloca-se como meio eficaz de destacar a anomia de quaisquer desviantes - ainda que isso não se paute em evidências reais -, com o fim de estabelecer distinção diante deles.

Um segundo conjunto transversal de apelidos, ainda mais robusto, mobiliza nomes de animais dos mais diversos. Essa recorrência conduz à abordagem clássica de Leach (1983) acerca das categorias animais que perpassam insultos verbais em diferentes sociedades. Nessa análise, o autor postula que ganha "contrapartida linguística"

6 São exemplos emblemáticos: o Programa Bolsa Família (Lei n. 10.836/2004); as cotas étnico-raciais de ingresso no ensino universitário federal (Lei n.12.711/2012); o Programa Brasil sem Homofobia lançado em 2004; além da Política de Educação Especial na Perspectiva da Educação Inclusiva, datada de 2008 
tudo aquilo que é "tabu", ou seja, todos aqueles elementos considerados ameaçadores a hierarquias de poder dentro das ordenações sociais.

Em embates "estabelecidos-outsiders" (Elias e Scotson 2000) como aqueles em análise aqui, a humanidade desses últimos aparece, permanentemente, desautorizada pelos primeiros, por meio de uma alegada não adequação aos padrões reconhecidos de "normalidade". É desde esse ponto de vista, portanto, que fazem sentido os apelidos animalescos. Se as ofensas com animais indicam, portanto, serem assertivas para erguer fronteiras de distinção, resta problematizar porque estes e não outros seres não humanos surgem repetidamente empregados.

Uma argumentação reside na igualmente clássica análise de Lévi-Strauss (1986) sobre o fenômeno do totemismo. De acordo com ele, animais emergem em profusão, seja como totens, seja em insultos, porque conformam uma "realidade sensivel" imediatamente disponivel aos homens para refletirem sobre e classificarem as diferenças humanas. As conexões mentais que se estabelecem nesse panorama não são arbitrárias, utilitárias ou contíguas, mas lógicas, relacionais e metafóricas. Ou seja, eficazes para pensar e trabalhar a alteridade em um âmbito intelectual.

O terceiro e último grupo perpendicular de apelidos abrange referências chamadas de figurativas, no interior das quais a exploração de recursos de linguagem se revelou deveras astuta. Dois apelidos desse conjunto, certamente, mostram-se enigmáticos no quadro antes exposto: Victor Hugo e LV, ambos coletados no universo privado de ensino. O primeiro faz menção ao estilista uruguaio, radicado no Brasil, famoso por suas bolsas de valores nada singelos. Contou-me uma docente que o pai de um aluno foi ao colégio queixar-se do bullying perpetrado por colegas contra o filho, posto chamarem-no cotidianamente de Victor Hugo. A educadora, de imediato, pouco entendeu. O pai então explicou-lhe que se tratava de um eufemismo para a imputação de gay.

Os colegas, desse modo, retiraram uma referência do mundo da moda, onde a presença de sexualidades desafiadoras do padrão heteronormativo se evidencia comum, para elaborar uma intimidação velada, porquanto a escola estar muito atenta a esse tipo de comportamento, passivel de punição após a emergência da noção de bullying. A construção do termo $L V$ demonstra lógica parecida: trata-se da abreviatura da grife francesa Louis Vuitton, também famosa por bolsas caras. Uma professora confidenciou-me que estudantes utilizavam a sigla para denominar, de forma constrangedora, alunos agraciados com bolsas de estudos, demarcando assim desigualdades de poder aquisitivo.

\section{Considerações finais}

O construto de bullying certamente nomeia comportamentos que não são novidade nos meios educacionais. A despeito disso, emerge na contemporaneidade brasileira como uma categoria que dá nova voz a sensibilidades sobre segregação, violência, sofrimento e reparação em meio às vivências estudantis. Essa noção traz consigo, portanto, um novo vocabulário, desencadeador de "efeitos performativos" sobre a realidade. Tais impactos ultrapassam as fronteiras acadêmicas do termo e revelam a "inteligência social dos atores" mirins, a explorar no dia a dia "dimensões táticas" (Fassin e Rechtman 2009) em torno do construto, seja para se defender, seja para subalternizar.

O estudo de caso aqui exposto buscou ilustrar essa conjuntura. À semelhança do observado por Lewis (2015), a etnografia que realizei demonstra uma percepção de mundo das crianças nada inferior ou incompleta, mas sim peculiar. Tal singularidade de visão demandou, por conseguinte, um protocolo próprio de pesquisa antropológica, que privilegiou a fluidez de observações sistemáticas, conversas informais e interlocuções diretas entre pares via grupos focais, em detrimento, por exemplo, da fixidez de entrevistas pessoais estruturadas.

Ao apostar nesses métodos, constatou-se que os infantes "[...] interagem ativamente com os significantes e práticas sociais que compõem suas vidas diárias" (Lewis 2015, 255), inseridas em uma ordem sociológica segregacionista. A etnografia com esses sujeitos abre assim espaços para visualizar, por certo em termos particulares, determinados fatos com uma "I...] clareza que elas (as crianças) nos cospem na cara" (Cohn 2013, 239). Dentre tais constatações, está a inverossimilhança da aspiração de certos educadores de vetar termos risiveis nos ambientes 
de aprendizagem, apesar da propagação da noção de bullying como recurso acusatório.

Logo, à luz do ferramental teórico-metodológico a balizar essa etnografia, argumento que as crianças conhecem e exploram com perspicácia as propriedades rituais do riso canalizadas, segundo Douglas (1993), para fomentar socialidades na mesma medida com que canalizam animosidades. A profusão destas últimas, na forma de atribuição de apelidos e da demarcação de casos de bullying, não conforma surpresa ou coincidência na cena cotidiana escolar do Brasil. Um país secularmente recheado de desigualdades, muito recentemente colocadas em turbulência, tanto pelo que políticas públicas de inclusão e diversidade precursoras transformaram ao longo dos anos 2000, quanto pelo que de iniquidade, apesar delas, ainda permanece intocado.

\section{Referências}

Bazzo, Juliane. 2018. "Agora tudo é bullying": uma mirada antropológica sobre a agência de uma categoria de acusação no cotidiano brasileiro. Tese em Antropologia Social, UFRGS, Porto Alegre.

Becker, Howard S. 2008. Outsiders: estudo de sociologia do desvio. Rio de Janeiro: Zahar.

Cohn, Clarice. 2013. Concepções de infância e infâncias: um estado da arte da antropologia da criança no Brasil. Civitas: Revista de Ciências Sociais 13 (2): 221-244. https:// doi.org/10.15448/1984-7289.2013.2.15478.

Douglas, Mary. Jokes. 1993. In Implicit meanings: essays in anthropology, editado por Mary Douglas, 90-114. London: Routledge \& Kegan Paul.

Duarte, Luiz Fernando D. 1981. Identidade social e padrões de "agressividade verbal" em um grupo de trabalhadores urbanos. Boletim do Museu Nacional n. 36: 1-36.

Elias, Norbert e John L. Scotson. 2000. Introdução: ensaio teórico sobre as relações estabelecidos-outsiders. In Os estabelecidos e os outsiders: sociologia das relações de poder a partir de uma pequena comunidade. 19-50. Rio de Janeiro: Zahar.

Fassin, Didier e Richard Rechtman. 2009. The empire of trauma: an inquiry into the condition of victimhood. Princeton, Oxford: Princeton University Press.

Fernandes, Florestan. 2004. As "trocinhas" do Bom Retiro. Pro-posições 15 (1): 229-250.

Horn, Claudia I. 2013. Pesquisa etnográfica com crianças: algumas possibilidades de investigação. Revista Enfoques 13 (1): 1-19.

Lagrou, Els. 2009. O riso grotesco e o riso festivo: narrativas e performances Kaxinawa. In As festas e os dias: ritos e sociabilidades festivas, organizado por Maria Laura V. C. Cavalcanti e José Reginaldo S. Gonçalves, 169-196. Rio de Janeiro: Contra Capa.
Leach, Edmund R. 1983. Aspectos antropológicos da linguagem: categorias animais e insulto verbal. In Leach, organizado por Roberto DaMatta, 170-198. São Paulo: Ática.

Lévi-Strauss, Claude. 1986. O totemismo hoje. Lisboa: Edições 70

Lewis, Liana. 2015. Infância e agenciamento sobre representações raciais. In Antropologia em novos campos de atuação: debates e tensões, organizado por Mónica Franch, Maristela Andrade e Lara Amorin, 251-270. João Pessoa: Midia Gráfica e Editora.

Maggie, Yvonee e Ana Prado. 2014. O que muda e o que permanece o mesmo nas escolas cariocas: culturas de gestão e as representações dos estudantes. In Abordagens etnográficas sobre educação: adentrando os muros das escolas, organizado por Simoni L. Guedes e Tatiana A. Cipiniuk, 69-81. Niterói: Alternativa.

Noel, Gabriel. 2009. La conflictividad cotidiana en el escenario escolar: una perspectiva etnográfica. San Martin: Unsam Edita.

Olweus, Dan. 2006. Bullying at school: what we know and what we can do? Malden, MA: Blackwell Publishing.

Ortner, Sherry B. 2007. Poder e projetos: reflexões sobre a agência. In Conferências e diálogos: saberes e práticas antropológicas, organizado por Miriam P. Grossi, Cornelia Eckert e Peter Fry, 45-80. Blumenau: Nova Letra.

Pereira, Alexandre B. 2010. "A maior zoeira": experiências juvenis na periferia de São Paulo. Tese em Antropologia Social, USP, São Paulo.

Sarti, Cynthia, Éverton L. Pereira e Nádia Meinerz. 2017. Avanços da resolução 510/2016 e impasses do Sistema Cep/Conep. Revista Mundaú 2: 8-21.

Smolka, Ana Luiza Bustamente, Adriana Lia F. de Laplane, Lavinia L. S. Magiolino e Débora Dainez. 2015. O problema da avaliação das habilidades socioemocionais como política pública: explicitando controvérsias e argumentos. Educação \& Sociedade 36 (130): 219-242. https://doi.org/10.1590/ES0101-73302015150030.

Souza, Jessé (org.). 2009. Ralé brasileira: quem é e como vive. Belo Horizonte: Editora da UFMG.

Tambiah, Stanley J. 1985. A performative approach to ritual. In Culture, thought, and social action, edited by Stamley J. Tambiah, 123-166. Cambridge: Harvard University Press.

Velho, Gilberto. 1981. Individualismo e cultura: notas para uma antropologia da sociedade contemporânea. Rio de Janeiro: Zahar.

\section{Juliane Bazzo}

Doutora em Antropologia Social pela Universidade Federal do Rio Grande do Sul (Ufrgs), Porto Alegre, RS, Brasil, com estágio doutoral na City University of New York (Cuny), Queens College e The Graduate Center, New York, EUA. Professora substituta do Departamento de Antropologia da Universidade Federal do Paraná (UFPR), Curitiba, PR, Brasil. 